\title{
Contribución al conocimiento de la historia de la violencia en el Perú
}

\author{
Contribution to the knowledge of history of violence in Peru
}

\begin{abstract}
Fausto Garmendia Lorena ${ }^{1,2}$
${ }_{1}^{1}$ Profesor Principal de Medicina; Miembro Permanente, Instituto de Investigaciones Clinica; Coordinador, Programa Permanente de Capacitación para la Atención Integral de las Victimas de la Violencia, Facultad de Medicina, Universidad Nacional Mayor de San Marcos, Lima, Perú.

${ }^{2}$ Academia Nacional de Medicina.
\end{abstract}

\begin{abstract}
Resumen
Esta investigación de carácter histórico describe todas las formas de violencia que se han producido en el Perú desde la formación de las culturas pre-Inca, Inca, la Conquista del Perú por los españoles, la etapa del Virreinato, la Independencia del dominio español, la tumultuosa historia de la República, en la que se resalta el conflicto interno de los años 1980 al 2000 y se finaliza con las formas de violencia más prevalentes en el Perú de hoy.
\end{abstract}

Palabras clave. Violencia; Historia; Perú.

Abstract

This historical research describes all forms of violence occurred in Peru since the beginning of pre-Inca and Inca cultures, conquest of Peru by the Spaniards, viceroyalty period, independence from the Spanish possession, tumultuous Republic history, standing out the internal conflict of years 1980-2000, and ending with the most prevalent forms of violence in Peru of today.

Keywords. Violence; History; Peru.

An Fac med. 2016;77(1):45-50 / http://dx.doi.org/10.15381/anales.v77i1.11552

\section{INTRODUCCIÓN}

La violencia está ligada a la historia de la humanidad. En todos los tiempos se han producido innumerables conflictos que llevan a la presunción que la violencia forma parte de la naturaleza humana. En la historia del Perú, del mismo modo se puede apreciar que desde las culturas pre-inca, la expansión de la cultura Inca, la conquista del Perú por los españoles, los quinientos años de la colonia o virreinato y los 194 años de la República se han producido diversas formas de violencia, en las que se han violado, con reiteración, esenciales derechos humanos.

Los derechos humanos son los derechos personales y colectivos, reconocidos por las sociedades organizadas en forma internacional, inherentes al respeto de la dignidad de la persona humana. Fueron reconocidos y promulgados en el año 1948 mediante la Declaración Universal de los Derechos Humanos (DDHH) por la III Asamblea General de las Naciones Unidas ${ }^{(1)}$. En el Perú estos derechos se elevaron a la categoría de Pactos Colectivos el 16 de diciembre de 1966 y muchos de sus principios han sido incorporados a la actual Constitución de la República ${ }^{(2)}$.

Se han publicado pocos aportes específicos sobre la historia de la violencia en el Perú, por lo que ha sido necesario extraerlos de las narraciones generales de cronistas ${ }^{(3)}$, historiadores ${ }^{(4)}$, antropólogos y arqueólogos de las diferentes etapas de la historia nacional ${ }^{(5,6)}$.
En el origen del hombre americano, la mayoría de historiadores y antropólogos coinciden que pobladores de Asia migraron a América del Norte por el estrecho de Bering 25000 años aC y que llegaron desde el norte a los Andes peruanos 12000 años antes de nuestra era, donde se establecieron y desarrollaron durante diferentes etapas.

En el Período Lítico (12 000-6 000 $\mathrm{aC})$, los primeros cazadores-recolectores, que eran nómades, dejaron restos de su presencia en Talara, Cumbe, Paiján, La Cumbre, Quishkipuncu, Lauricocha, Ambo, Ranracancha, Pachamachay, Panalacua, Ancón, Chivateros, Tres Ventanas, Pikimachay, Puente, Jaimamachay, Huanaqueros, Sumbay, Toquepala ${ }^{(7)}$. De estos asenta- 
mientos humanos, destaca Lauricocha, descubierta por el antropólogo peruano Augusto Cardich, en 1958, situado en la provincia de Lauricocha, departamento de Huánuco, donde los antiguos pobladores vivían en cuevas, dentro de las cuales se encontró restos humanos y dibujos rupestres con representaciones de la caza de camélidos suramericanos.

En el Período Arcaico (6 000-1 800 $\mathrm{aC})$, en parte aún cazadores-recolectores, iniciaron en forma incipiente el cultivo de las tierras y con ello el sedentarismo por los frutos obtenidos mediante la acción comunitaria. Cáceres ${ }^{(7)}$ muestra un mapa de la distribución de las comunidades que existieron en la costa, como Huaca Prieta, Huaca Negra, Alto Salaverry, La Galgada, Salinas de Chao, Las Aldas, Los Gavilanes, Huaricoto, Culebras, Áspero, Caral, Río Seco, Ancón, El Paraíso, Chira Villa, Chilca, Asia, Cabeza Larga, Otuma y, en la sierra, Pandanche, Piruro, Kotosh, Quisquipisa. Entre ellas destaca Caral, la ciudad más antigua de América, ubicada en el valle de Supe.

Del Período Formativo Inferior (1 800-1 $200 \mathrm{aC}$ ), en el que se inicia el desarrollo de la cerámica, telares y metalurgia, también denominado PreChavín, se tiene información en la costa de los grupos sociales de Negritos, Huaca Lucía, Caballo Muerto, Guañape, Cerro Sechín, Las Haldas, Ancón, Garagay, Mina Perdida, La Florida, Cardal, Curayacu ('Venus de Curayacu'), Erizo, Hacha y, en la sierra, Pacopampa. Atoril, Wayrajirca, Kotosh, Marcavalle, Qaluyo, Chiripa y, en la selva, Tutishcainyo.

\section{PERÙ PRE INCA}

Es a partir del Período Formativo Medio (1 200 a $300 \mathrm{aC})$ que se tiene una información clara del inicio de la formación de culturas, comenzando con la de Chavín y posteriormente se desarrollaron, tanto en la costa como en la región andina y la selva, diversas culturas, que estuvieron sometidas a continuos procesos de conquista de unos pueblos sobre otros, lo que conllevó a la utilización de la violencia física, psicológica, social y cultural, dada la diversidad de su estructura social y religiosa. Entre esas culturas destacan Tiahuanaco, Wari, Paracas, Nazca, Chachapoyas, Mochica, Chimú.

Aparte de las acciones armadas, de conquista, sojuzgamiento y esclavización, se debe considerar a las actividades mágico-religiosas de naturaleza ritual, entre las que destacan los sacrificios humanos y las formas de entierro, diferentes de acuerdo al estatus social. Los grandes señores, como el de Sipán, eran enterrados con familiares y personas de su servicio. Los entierros reflejaban la función y lugar de cada persona dentro de su estructura social.

\section{ÉPOCA INCA}

La cultura Inca se desarrolla a partir del año $1400 \mathrm{dC}$ y se expande no solo por el territorio del Perú actual, sino que por el norte llega hasta Ecuador y Colombia y por el sur hasta el rio Maule en Chile, parte de Bolivia y el norte de Argentina ${ }^{(4)}$. Los Incas fueron guerreros y sojuzgaron a muchos otros pueblos mediante la confrontación bélica y todas sus consecuencias de violencia. La existencia de una casta militar, la construcción de fortalezas y la utilización de diversas armas como las makanas, huarakas, así como el desarrollo de la medicina de guerra mediante las trepanaciones e inmovilizaciones de miembros fracturados demuestran su preparación para la guerra. Tuvieron enemigos permanentes como los Chancas y los Huancas, con los que además utilizaron otras formas de violencia como los mitimaes o exilios forzosos; impusieron su idioma, sus creencias religiosas y su organización social. Poco antes de la llegada de los españoles, se produjo una guerra civil a la muerte de Huayna Capaq y del príncipe heredero Ninan Cuyuchi; sus hijos Atahuallpa de la panaca de Quito y Huáscar de la panaca del Cusco inician una confrontación bélica para mantener la hegemonía en el poder del imperio. Las huestes de Atahuallpa, liderados por sus generales Quizquiz y Challcuchimac, avasallaron y mataron a Huáscar y a la familia imperial cusqueña; solo algunos como Manco Inca consiguieron huir a Vilcabamba, sobreviviendo a la masacre.

\section{LA CONQUISTA DEL PERÚ}

La conquista del Perú por los españoles no fue pacífica. Por el contrario, se expresó mediante la violencia de la confrontación armada, que tuvo éxito muy rápido, que se explica por diversas razones; primero, el imperio incaico no se pudo consolidar totalmente desde que un siglo de existencia resultó corto para asentar todo el poderío de esta cultura; segundo, los españoles tuvieron la ayuda de los pueblos que anteriormente habían sido sojuzgados por los Incas y además por el resentimiento de los sobrevivientes de la panaca de Huáscar que veían a los españoles como aliados contra Atahuallpa y los pueblos de la panaca de Quito. El ajusticiamiento de Atahuallpa y la masacre de su ejército fue un episodio de extrema crueldad; el amancebamiento de las mujeres nativas configura la violencia por abuso sexual; los españoles despojaron a los nativos de sus propiedades y riquezas en todo el territorio dominado por los Incas.

\section{LA ÉPOCA dE LA COLONIA O VIRREINATO}

Después de la conquista, el reino de España quebró toda la estructura política y social de la cultura Inca mediante la violencia de diverso tipo; se expresó por el poder ejercido del vencedor hacia los vencidos. La corona española instituyó las Encomiendas, mediante las cuales encargaba a los conquistadores asumir la función de tomar a su cargo un determinado número de nativos y de tierras, de acuerdo a su rango en la estructura política del momento, que tuvo la doble finalidad de obtener riquezas e integrar al indígena a la cultura española por medio de la evangelización 
y la prédica de costumbres cristianas; pero, en la práctica fue un instrumento de cruel esclavización, en la que la vida de los nativos no tenía valor alguno, tanto que trajo las denuncias de Fray Antonio Montesinos y Bartolomé de la Casas. Además, se les impuso una nueva religión, se destruyeron los templos para sustituirlos por iglesias, despojaron a los nativos de sus propiedades y de sus fuentes de riqueza, se implantó los trabajos forzados de las mitas para la explotación de las minas, que cobraron la vida de millones de pobladores; se calcula que en ese período la población del Perú disminuyó a la mitad. Se destruyó la estructura del gobierno y de la sociedad. Quedan sin embargo rezagos de esa cultura extraordinaria que no pudieron ser eliminados por la codicia de los encomenderos, como el ayllu, el aini y el propio idioma, que prevalecen después de tantos siglos de violencia e intolerancia, en los que se ha ejercido un proceso de transculturación aplicable en todo su contexto y significado.

En esa etapa hubo también otras expresiones de beligerancia, como el levantamiento de Manco Inca, que duró de 1536 a 1572 , que estuvo a punto de derrotar a los españoles en el sitio del Cusco el 3 de mayo de 1536. Sin embargo, la mayor capacidad bélica de los españoles determinó la derrota en la fortaleza de Sacsayhuaman donde se inmoló Cahuide antes de caer preso. Manco Inca se retiró a Vilcabamba y fue muerto por la acción traidora de almagristas, a los que había cobijado tras su persecución por los pizarristas; lo sucedieron en la resistencia los incas Sayri Túpac, Tito Quispe Yupanqui y Túpac Amaru I

Las guerras civiles entre los conquistadores se produjeron por la codicia de poseer más tierras y riqueza, así como mayor poder político. Diego de Almagro el Viejo fue ejecutado después de perder en la batalla de las Salinas, al sur del Cusco y Francisco Pizarro fue asesinado por los almagristas caídos en desgracia.
El levantamiento de Gonzalo Pizarro, de 1544 a 1548, denominado de los encomenderos, por estar contrarios a las Nuevas Leyes que restringían beneficios en sus encomiendas, fue sofocado por acción del inmisericorde religioso, político, diplomático y soldado Pedro de la Gasca, quien en la batalla de Jaquijahuana venció a Gonzalo Pizarro y su cruel maese de Campo Francisco de Carbajal, siendo ejecutados y expuestas sus cabezas para escarmiento de quienes volvieran a levantarse. La intolerancia religiosa de la Inquisición se hizo evidente también en el Perú de 1570 hasta 1814 . Una visita al Museo de la Inquisición permite comprobar todos los instrumentos de tortura que se emplearon para obtener la confesión de los denunciados por supuestos actos de idolatría y otras acciones contrarias a la fe católica.

\section{LA INDEPENDENCIA}

El proceso de la independencia comenzó con los primeros grupos insurgentes a partir de 1780 con el conato de rebelión liderado por Lorenzo Farfán de los Godos, en el Cusco, denominado el Levantamiento de los Plateros, y Bernardo Pumayalli Tambohuacso, Cacique de Pisac, que se llevó a cabo como protesta a la imposición de la Aduana.

El levantamiento de José Gabriel Condorcanqui Noguera, Marqués de Oropesa, que tomó el nombre de Túpac Amaru II, se desarrolló de 1870 a 1871, constituyó el levantamiento indígena más extenso surgido contra todos los abusos como las alcabalas, tributos indígenas, las mitas mineras, la esclavitud, en el que se abogaba por primera vez la independencia política, económica y social de todas las Américas. Sofocada por el ejército realista culminó con su ejecución en la plaza mayor del Cusco, junto a su esposa la valerosa Micaela Bastidas y sus hijos, en la forma más cruel ${ }^{(8)}$. Posteriormente, destacan los levantamientos de los hermanos Angulo, las conversaciones separatistas en el Colegio de Medicina de San Fernando (1808), la rebelión de Francisco de Zela y Arizaga en 1811 en Tacna que concluye con la Expedición Libertadora de San Martín y la declaración de la independencia el 28 de julio de $1821^{(9)}$. Sin embargo, las tropas realistas persisten en diversas confrontaciones militares que recién terminan en 1824 con las batallas de Junín y Ayacucho. En todo el proceso se produjo una serie de eventos de violencia por la confrontación armada, ejecuciones sumarias y las represalias de las fuerzas realistas, como las ejercidas por los militares Ricafort y Catarralá quienes arrasaron y saquearon pueblos de Junín $\mathrm{y}$ asesinaron a pobladores indefensos.

\section{PERÚ REPUBLICANO}

Consolidada la independencia, el Perú tuvo una vida política inestable, difícil, con múltiples hechos de confrontación tanto interna como internacional, durante todo el siglo XIX. En el frente interno se sucedieron múltiples levantamientos y revoluciones por la supremacía entre caudillos militares como Gamarra, Santa Cruz, Salaverry, Castilla, Vivanco, Piérola, Cáceres, etc, por el poder político y social. Como consecuencia de ello se sucedieron 109 gobiernos; solo entre 1824 a 1845 hubo 53 gobiernos y 6 constituciones; en 1838 hubo 7 gobiernos al mismo tiempo, que fueron el producto de rebeliones, revoluciones, designaciones, gobiernos provisorios y gobiernos constitucionales mediante elecciones; algunos de ellos duraron horas o días y pocos lograron completar el tiempo para el cual habían sido elegidos. El 22 de julio de 1872 se sublevan los hermanos Tomas, Marcelino, Silvestre y Marceliano Gutiérrez y dan muerte al presidente José Balta; el pueblo reacciona y dan muerte y cuelgan los cuerpos de los hermanos Gutiérrez en las torres de la catedral de Lima. Manuel Pardo y Lavalle, fundador del Partido Civil y primer presidente constitucional del Perú en el período de 1872-76, fue asesinado el 16 de noviembre de 1878 por el sargento Melchor Montoya cuando 
ingresaba al Congreso en su calidad de presidente del mismo.

Se produjeron dos conflictos internacionales, la denominada Guerra con España, que intentó infructuosamente recuperar sus colonias y que concluyó con la Batalla Naval del 2 de Mayo de 1866 y en 1879 se inicia la denominada Guerra del Pacífico, en la que Chile invadió el Perú en una campaña militar premeditada, con todas las violaciones que se producen en una confrontación militar. Las bajas peruanas en San Juan y Miraflores fueron muy altas; se menciona como la dorada juventud limeña, a menudo acusada de frívola, peleó y murió al pie de los reductos. Muchas familias en Lima estuvieron de duelo; sin embargo, la violencia continuaría a través del saqueo, con la depredación cultural de Lima, el saqueo de libros de la biblioteca nacional. La contribución de la Facultad de Medicina en la Guerra del Pacífico fue cuantitativa y cualitativamente importante, pues muchos de los estudiantes de medicina se inmolaron en la violenta guerra del Pacífico o participaron en las ambulancias. Este conflicto terminó con el Tratado de Ancón en 1883 que significó además la perdida de los territorios de Arica y Tarapacá. Andrés Avelino Cáceres nunca se rindió, llevando a cabo la llamada campaña de la Breña, de 1881 a 1883, en la que mantuvo a las fuerzas chilenas en permanente jaque.

En el siglo XX destacan la revolución del coronel Oscar R. Benavides que derrocó a Guillermo Billinghurst, en 1914; el golpe de estado del 4 de julio de 1919 de Augusto B Leguía, que dio lugar a su gobierno de 11 años luego de sucesivas reelecciones. Luego, la revolución del comandante Luis Miguel Sánchez Cerro, quien se levanta el 27 de agosto de 1930 en Arequipa y derroca a Augusto B. Leguía, quien muere en prisión. El 30 de abril de 1933 se llevó a cabo el asesinato de Luis Sánchez Cerro, mientras pasaba revista a las tropas que debían participar en la confrontación con Colombia por el llamado triángulo de Leticia, asumiendo la presidencia el general Oscar R. Be- navides, quien lleva a cabo un gobierno dictatorial hasta 1939. En ese año es elegido presidente constitucional el Dr. Manuel Prado Ugarteche, quien tuvo que afrontar el conflicto con Ecuador en la llamada Guerra de 1941, que concluyó con el Protocolo de Paz, Amistad y Límites de Río de Janeiro el 29 de enero de 1942. En 1945 lo sucedió en el gobierno, también en elecciones generales, el doctor Luis Bustamante y Rivero, quien no pudo concluir su mandato al ser depuesto mediante una revolución por el general Manuel A Odría, el 29 de octubre de 1948. Odría permaneció en el poder en un gobierno autocrático hasta 1956, cuando en elecciones generales es elegido para un segundo mandato el Dr. Manuel Prado Ugarteche, quien tampoco culminó su gobierno; faltando pocos meses para concluir su mandato se produce la revolución militar presidida por el general Ricardo Pérez Godoy, que posteriormente es reemplazado por un triunvirato militar. El 28 de julio de 1963, en elecciones generales asume el gobierno el Arquitecto Fernando Belaúnde Terry, en cuyo gobierno se produjo un corto conflicto con el Ecuador denominado Falso Paquisha, del 22 al 26 de enero de 1981. El 3 de octubre de 1968 se produce la Revolución de la Fuerzas Armadas conducida por el general Juan Velazco Alvarado quien derroca al presidente Belaúnde y en un relevo institucional es reemplazado por el general Francisco Morales Bermúdez, en 1975. En 1980 es elegido para un segundo mandato presidencial el arquitecto Fernando Belaúnde Terry, quien después en sucesivas elecciones generales es sucedido por el Dr. Alan García (1985-1990) y el Ing. Alberto Fujimori. Este último mandatario disuelve el congreso el 5 de abril del 1992; en el denominado autogolpe, efectúa cambios en la constitución que le permiten reelegirse hasta en tres oportunidades. Del 26 de enero al 28 de febrero de 1995, se tuvo que enfrentar el conflicto del Alto Cenepa con el Ecuador. El Ing. Alberto Fujimori, ante la presión popular y del Congreso de la República por denuncias de corrupción, presentó su renuncia. El
Congreso de la República eligió al Dr. Valentín Paniagua Corazao como presidente en un gobierno de transición el 22 de noviembre del 2000; entre otros aspectos nombra la Comisión de la Verdad y Reconciliación para evaluar todo lo acontecido en el conflicto interno de 1980 al 2000.

En el siglo XXI fue elegido presidente de la república el Dr. Alejandro Toledo Manrique el 28 de julio del 2001; durante este gobierno se produjo el levantamiento del mayor Antauro Humala denominado Andahuaylazo en Andahuaylas, Apurímac, en el que fallecieron 4 policías y 2 insurgentes. Posteriormente, lo han sucedido el Dr. Alan García (2006-2011) y el comandante Ollanta Humala (2011-2016).

\section{CONFLICTO ARMADO INTERNO DE 1980 A 2000}

De 1980 al año 2000, se produce un conflicto armado interno provocado por los movimientos terroristas Sendero Luminoso y el Movimiento Revolucionario Túpac Amaru, cuyas características y consecuencias han sido señaladas por la Comisión de la Verdad y Reconciliación ${ }^{(10)}$. En ese lapso se produjeron diversas formas de violencia, tales como acciones armadas, genocidios, sabotajes, aniquilamientos selectivos, masacres, secuestros, torturas, exilio forzado, explosión de bombas, apagones por destrucción de torres de alta tensión eléctrica, paros armados, cautiverio, esclavización de comunidades e intimidación colectiva, entre otros. El conflicto cobró 69280 muertes y desapariciones, $75 \%$ de los cuales eran hablantes de lenguas nativas, $79 \%$ campesinos, $56 \%$ dedicados a actividades agropecuarias, $68 \%$ con educación primaria o menor; quedaron 20000 viudas, 40000 huérfanos, 435 comunidades fueron arrasadas, sinnúmero de desplazados, 1,5 a 2 millones de afectados directamente $y$, al final, mayor pobreza. 


\section{LA VIOLENCIA EN EL PERÚ DEL 2000 AL 2015}

En este tiempo se ha tomado conciencia y puesto atención a otras formas de violencia que siempre han existido, como la autoinflingida, interpersonal llevada en agravio de la mujer, los niños, los adultos mayores,; además, han aparecido otras formas de violencia o se han tornados más intensas, como la económica, delincuencial, laboral, ecológica, que violan aspectos importantes de los derechos humanos y que podrían ser consideradas como emergentes o reemergentes. Estas formas de violencia se encuentran descritas con mayor detalle en el trabajo La violencia en el Perú al $2015^{(11)}$.

\section{Violencia autoinflingida}

Entre los años 2012 a 2014, se ha registrado una prevalencia de 305 a 334 suicidios consumados anuales a nivel nacional ${ }^{(12)}$, cifras a las cuales se debería agregar la prevalencia de la conducta suicida que comprende a la ideación y al intento de suicidio ${ }^{(13)}$.

\section{Violencia contra la mujer}

La violencia psicológica contra la mujer se encuentra en el rango del $70 \%$ y no ha variado del 2009 al 2014. En el año 2000 la violencia física a nivel nacional alcanzaba el 41,2\%, con una distribución regional que fluctuaba entre 29\% y $57,3 \%$. En el año 2014, el promedio se redujo a $32,3 \%$ con una distribución regional diferente, que varió entre $22,7 \%$ y $46,7 \%$. Las denuncias por violencia sexual a mujeres mayores de 18 años ha fluctuado entre 1200 y 1600 por año, en los años 2011 a 2013, la gran mayoría en el ámbito de Lima. Las cifras por cierto son mayores, desde que una parte de las violaciones no son denunciadas.

En el quinquenio 2010 a 2014 el total de feminicidios, entre los efectivizados y tentativas, ha llegado a la cifra de 282 en los años 2013 y 2014. En el 90\% de casos el victimario fue una persona conocida o relacionada con la víctima ${ }^{(14)}$.

\section{Violencia infanto-juvenil}

La mayoría de los actos de violencia se producen dentro del ámbito familiar, sea por acción o por omisión o negligencia ${ }^{(15,16)}$. En el año 2014, se efectuaron 11097 denuncias de violencia familiar en personas de 0 a 17 años, de las cuales $57,05 \%$ fueron mujeres y $42,94 \%$ varones.

El bullying o acoso escolar es muy prevalente, Oliveros y col. han comprobado la existencia de bullying en 48\% de niños encuestados en colegios estatales de Lima Este, Ayacucho, Sicuani (Cusco) y San Martín de Pangoa (Satipo, Junín) y 54,7\% en un colegio privado de Lima ciudad ${ }^{(17,18)}$.

\section{Violencia al adulto mayor}

Lachs y Pillemer han definido las siguientes formas de violencia ocasionada a los adultos mayores: física, psicológica o verbal, sexual, por negligencia y de carácter económico ${ }^{(19)}$. El maltrato psicológico a la población adulta mayor es el más frecuente en forma de insultos, humillaciones, amenazas de muerte, rechazo, perpetrada por los hijos y familiares cercanos.

\section{Formas emergentes y reemergentes de violencia}

La violencia económica, la inseguridad ciudadana por violencia delincuencial, la violencia laboral y violencia ecológica derivada de los cambios que ha producido la humanidad a la naturaleza son en la actualidad las formas de violencia más preocupantes que indudablemente violan los derechos humanos.

En la violencia de carácter económico se priva la utilización de fondos públicos para la población más necesitada. En primer lugar está la corrupción; en la actualidad un número importante de gobernadores regionales, alcaldes, magistrados, políticos, asesores, inclusive ex presidentes se encuentran en situación de encarcelados, no habidos o cuestionados por malos manejos de los recursos utilizados durante su gestión; pero, la corrupción llega también a niveles de menor rango, mediante la figura de coimas para diferentes actividades de carácter económico. Bajo este mismo concepto está la evasión tributaria en todas sus formas, que llega a los 25000 millones de soles anuales, 80\% de los cuales corresponde a la efectuada por la minería y construcción informales e ilegales.

La violencia delincuencial está conduciendo a una situación de gran inseguridad ciudadana, que contiene elementos de agresión física, psicológica y económica, llevada a cabo por personas dedicadas a la realización de actos ilícitos con fines de beneficio personal violando derechos humanos. Dentro de ellos se debe considerar al narcoterrorismo existente en el VRAEM, la extorsión y el sicariato, tanto en Lima, el Callao, La Libertad, Lambayeque, como en Piura, a lo que se debe agregar la trata de personas, la invasión de terrenos y tierras de propiedad estatal y privada $^{(20)}$.

La violencia de tipo laboral incluye al maltrato que existe en los centros laborales, a los sindicatos de accionar violento y a empresas con actuación negligente que ponen en riesgo la salud, vida y economía de los usuarios. En la actividad de la construcción han proliferado mafias o pseudo sindicatos que extorsionan, cometen homicidios mediante el sicariato descritos como ajustes de cuentas. En el transporte terrestre de pasajeros, entre el año 2005 y el 2014 se registró 531945 víctimas de accidentes de tránsito, con un saldo de 498954 heridos y 32991 muertos ${ }^{(21,22)}$, debido a violencia por negligencia, cometida tanto por las empresas de transportes como de los propios conductores, que en muchos casos constituyen homicidios culposos.

Denominamos Violencia Ecológica a todos los grandes cambios que ha producido el hombre al medio ambiente que violan los derechos humanos al afectar el bienestar, salud y vida de las personas ocasionadas por el calentamiento global, contaminación ambiental, la tala indiscriminada de los 
bosques, la minería ilegal como la que existe en Madre de Dios, la producción de los denominados agrocombustibles y los biodiesel, la producción de harina de pescado a base de la pesca de la anchoveta y otras especies marinas que se utiliza como abono cuando debería estar destinada al consumo humano, frente a la existencia de grandes poblaciones en condición de pobreza y extrema pobreza que sufren de hambre y desnutrición.

Al final de esta descripción podemos llegar a la conclusión que se ha efectuado una revisión panorámica de los hechos de violencia más importantes que se han suscitado a lo largo de la vida nacional, desde las antiguas culturas prehispánicas hasta nuestros días. Debemos resaltar, sin embargo, que nos queda una sensación persistente de preocupación y hasta desasosiego ante el incremento de la violencia en el ámbito familiar y social, frente a lo cual se debe despertar la necesidad de un compromiso general para luchar por una Cultura de Paz que permita el desarrollo de una sociedad más apacible, respetuosa y tolerante.

\section{REFERENCIAS BIBLIOGRÁFICAS}

1. Declaración Universal de Derechos Humanos Disponible en: http://www.un.org/es/documentos/ udhr/.
2. Constitución Politica del Perú. Disponible en: http://portal.jne.gob.pe/informacionlegal/constitucion\%20y\%20Leyes1/CONSTITUCION

3. Santisteban J. Los cronistas del Perú. Lima, Perú: Librería e Imprenta D. Miranda, 1946.

4. Rostworowski M. Historia del Tahuantinsuyo. 2da Ed. Lima: IEP/Promperú, 1999.

5. Cano B. Historia de la violencia en el Perú dentro de una perspectiva de salud integral. En: Calidad humana y ética en la atención de salud a personas afectadas por la violencia. Programa Permanente de Capacitación para la Atención Integral de la Victimas de la Violencia, Facultad de Medicina, UNMSM, 2006:2-7.

6. Garmendia F. Historia, Geografía y Epidemiologia de la Violencia en el Perú. En: Perales A, Morales R, Pinillos L ed. Curso Internacional sobre Violencia y su impacto en la salud. Lima, 2010.

7. Cáceres J. Culturas Prehispánicas del Perú. En. Grimanesa R. Enriquez Lovatón, ed, 2009.

8. Lewin B. La insurrección de Tupac Amaru y los Orígenes de la Independencia de Hispanoamérica, Compendio. Buenos Aires: Editorial Universitaria de Buenos Aires, Eudeba, 1963. Reproducido en El Perú y su Independencia, Antologia, volumen I, Época Precursora o de la Pre-Emancipación (17801819), Lima: Gráfica Industrial, 1971:17-82.

9. Pons Musso G. Cronologia de los acontecimientos. En El Perú y su Independencia, Antologia, volumen I, Época Precursora o de la Pre-Emancipación (1780-1819). Lima: Gráfica Industrial, 1971:115.

10. Comisión de la Verdad y Reconciliación. Informe Final, 2003. Disponible en: www.derechos.org/ nizkor/peru.

11. Garmendia F. La violencia en el Perú al 2015, en prensa.

12. Portal de la Sociedad Peruana de Prevención del Suicidio. Disponible en: http://www.spps.com.pe/ contactenos/.

13. Perales A, Sogi C. Conductas suicidas en estudiantes de medicina. Rev Psiquiatr Peru. 2000;56(1):8-13.

14. Portal del Ministerio de la Mujer y Poblaciones Vulnerables - Programa Nacional contra la Violencia Familiar y Sexual, 2014.
15. Cano CB. Patologia psiquiátrica en niños y adolescentes que habitan en zonas con antecedente de violencia social en el Perú. Diagnóstico 2006;45(4):164-9.

16. Ballona R, Chacón O, Zaldivar E y col. Manifestaciones cutáneas del maltrato infantil - Instituto de Salud del Niño 1995 - 2002 Dermatol Pediatr Lat. 2003;1(1):24-9.

17. Oliveros M, Barrientos A. Incidencia y factores de riesgo de la intimidación (bullying) en un colegio particular de Lima-Perú, 2007. Rev per pediatr. 2007;60(3):150-5.

18. Oliveros M, Figueroa L, Mayorga G y col. Violencia escolar (bullying) en Colegios Estatales de Primaria en el Perú. Rev Soc Peruana Pediatría. 2008;61(4):215-2

19. Lachs MS, Pillemer KA. Elder abuse. N Engl J Med. 2015 Nov 12;373(20):1947-56. doi: 10.1056/ NEJMra1404688.

20. Portal del Ministerio Público. Observatorio de Criminalidad. Informe deTrata de Personas, 2014.

21. Portal del Ministerio de Transportes y Comunicaciones/ Informes y Publicaciones/ Estadisticas/ Transportes/Servicios/Accidentes/Victimas de accidentes de Tránsito Fatales y no Fatales, según Características de Las Victimas: 2005-2014.

22. Caso A, Rey de Castro J, Rosales-Mayor E. Hábitos de sueño y accidentes de tránsito en conductores de omnibus interprovinciales de Arequipa, Perú. Rev Peru Med Exp Salud Publica. 2014;31(4):707-11.

Articulo recibido el 20 de noviembre de 2015 y aceptado para publicación el 30 de enero de 2016.

Conflicto de intereses. No existen en la presente publicación.

Correspondencia:

Dr. Fausto Garmendia Lorena

Correo electrónico: garmendiafausto@gmail.com 